DOI $10.15593 / 2224-9354 / 2017.2 .8$

УДК 316.74:2

\author{
И.М. Пудовкина
}

\title{
ТЕОРЕТИЧЕСКИЕ ОБОСНОВАНИЯ ТИПОВ РЕЛИГИОЗНОГО СОЗНАНИЯ КАК ПОЛИСЕМАНТИЧЕСКОГО ПОНЯТИЯ
}

\begin{abstract}
Рассматриваются теоретические подходы к классификации религиозного сознания, на основании которых предпринята попытка его типологии. Особое место занимает понятие религиозноподобного сознания, отражающего представления о религии в массовом сознании и сформированного под влиянием светских факторов. Вопрос о соотношении религии и современности и состоянии современного религиозного сознания с его многочисленными парадоксами, прямо противоположными заявлениями сегодня является ключевым при изучении постсекулярной действительности. Социальные науки последнего времени были сосредоточены на теориях секуляризации, постулировавшие несовместимость религиозного и светского мировоззрения, причем за последним было признано неоспоримое право на существование, тогда как первое было отодвинуто в приватную сфреру. Постсекулярное общество возвращает религии законное место в обществе, признавая за ней одну из возможных альтернатив и один из способов познания действительности. Постсекулярное общество в большей мере, чем секулярное общество, характеризуется, по словам Ш. Эйзенштадта, «множеством современностей», сам фракт существования которых оказывает решающее влияние на формирование религиозноподобного типа сознания, наиболее адекватно отражающее религиозную ситуацию современности. Другими словами, религиозноподобное сознание развивается не только под влиянием религиозных и светских традиций, но и нетрадиционных религиозных движений, индивидуальных предпочтений, определяющих самоидентификацию индивида, квазиверований. Результаты социологического исследования позволяют выделить и обосновать основные черты религиозноподобного сознания как характерного типа нашего времени.

Ключевые слова: религиозное сознание, типы религиозного сознания, религиозноподобное сознание, квазирелигия, религиозность.
\end{abstract}

Понятие «религиозное сознание», как и религиозность, имеет неоднозначный многомерный характер. Как доминирующей черте религиозного сознания религиозности посвящено много исследований отечественных и зарубежных ученых. Этой проблеме уделяли и уделяют внимание Е.В. Пруцкова, Ю.Ю. Синелина, В.Ф. Чеснокова, Д.М. Угринович, И.Н. Яблоков, Ч. Глок, Ё. Фукуяма, Д. Фолкнер, Г. де Йонг, Р. Старк и др., в конечном итоге констатировавшие невозможность создать универсальные, не изменяющиеся с течением времени параметры ее измерения, вследствие ее неоднозначного проявления в различных конфессиях, исторических периодах развития общества, а потому предлагающие различные концептуальные понятия для описания данного феномена, в числе которых частота посещаемости церковных служб, чтение канонической литературы, причастие, соблюдение постов, молитва [1, с. 19], важность религии для индивида, связи внутри конгрегации, участие в деятельности религиозных общин и т.д. [2, с. 277-278].

(С) Пудовкина И.М., 2017

Пудовкина Ирина Михайловна - старший преподаватель кафедры общенаучных дисциплин, Березниковский фрилиал ФГБОУ ВО «Пермский национальный исследовательский политехнический университет», e-mail: iri14250591@yandex.ru. 
Между тем термин «религиозное сознание» применяется исследователями в его однозначном универсальном значении. Такой подход обоснован возможностью изучения религиозного сознания как части общественного сознания и сознания в целом и на основе их сопоставления выявления сходства и различия.

Но многомерность понятия религиозного сознания была отмечена Э. Дюркгеймом, указавшим на различие религиозного мышления, религиозной деятельности и религиозной жизни у различных слоев населения теологов, пророков, монахов и мирян [3, с. 180].

В дальнейшем концепция Дюркгейма получила свое полное обоснование у М. Вебера, ставившего религиозное сознание и сознание в зависимости от понимания идеи спасения различными статусными группами, спецификой их профессиональной деятельности, образа жизни и географической среды проживания [4, с. 191-231].

Несколько ранее социологический подход к религиозному сознанию продемонстрировала русская религиозная философия в процессе дискуссии между западниками и славянофилами. Отметим, классификация религиозного сознания не являлась задачей философского спора, но его типы постепенно обозначились в процессе полемики, целью которой было решение вопроса об истине в сопоставлении европейских и русских религиозных ценностей. В частности, постулируя наследие русской философии XIX века, Г.В. Флоровский характеризует русский и западный тип религиозного сознания как два абсолютно противоположных явления, первый из которых описывается в терминах восхождения и совершенствования, второй - с точки зрения его регрессивного развития, отказа от веры под влиянием рационализма и прагматизма. Однако русское религиозное сознание Флоровский не рассматривает как единое целое, аргументируя свой подход наличием двух типов культур, культуры «дневной» и народной, традиционной или «ночной». К носителям первого типа культуры относилось образованное меньшинство, чье религиозное сознание формировалось под влиянием византийской христианской традиции, второй тип культуры представляет собой синтез народных языческих верований и христианства и являлся уделом большинства [5, с. 14-16].

Для Н.А. Бердяева критерием классификации русского религиозного сознания являлась категория святости, которая позволила ему по-иному сопоставить численные величины большинства и меньшинства. В результате такое состояние религиозного сознания, как святость, становится прерогативой лишь отдельных харизматических личностей, в то время как религиозное сознание абсолютного большинства рядовых верующих развивалось под влиянием опять же близкого социального окружения или «органического коллектива» с его устоявшимися профессиональными навыками и традиционным укладом жизни [6, с. 289-290].

Религиозное сознание личности святого и рядового верующего у Бердяева определяется как «простое сознание», распространенное среди боль- 
шинства, и космическое вселенское сознание, характерное для меньшинства, способного к мистическим озарениям, обладающего божественной сущностью и высокими нравственными и моральными качествами, по классификации Р. Бекка $[7$, с. 66, 70].

Еще более дифференцированный подход к русскому религиозному сознанию мы находим у Е.Ю. Скобцовой [8]. Типы религиозного сознания, выявленные и обоснованные ею, представляли собой результат церковных петровских реформ, секуляризации русского общества и формализации религиозной деятельности и жизни. В целом типы религиозного сознания и связанные с ним типы религиозного поведения [8, с. 14-29] заключают в себе девиантные установки с точки зрения традиционной религиозности, соответствуют типам индивидуального приспособления к религиозной политике государства и, основываясь на концепции Р. Мертона, могут рассматриваться как конформистский (синодальный) тип, для которого важен функциональный аспект религии, обеспечивающий статус, по словам Скобцовой, «благонадежного человека», что, в свою очередь, является фактором карьерного роста; ритуалистический (уставщический) тип, стремящийся к внешнему соблюдению мельчайших деталей обряда, но без внутреннего духовного переживания, и эстетический тип (религиозное поведение определяется как бегство), т.е. тип, сформированный под влиянием традиционных культурных ценностей, тогда как институциональный религиозный опыт оказывается невостребованным, а потому бесполезным [9, с. 256, 268-272].

3.И. Файнбург вводит в научный оборот понятие религиозноподобного сознания [10, с. 28], которому он придавал большое значение, но дальнейшая работа по конкретизации и разработке этого термина не была реализована в условиях атеистической идеологии. Между тем тип религиозноподобного сознания представляется сегодня актуальным и отражает сущность современного состояния религиозного сознания, сформированного под влиянием светской культуры, государственной идеологии, а также традиционных религиозных ценностей.

Понятие религиозноподобного сознания у Файнбурга основано на тезисе Маркса о ложном сознании как результате отчуждения человека от подлинных ценностей и его зависимости от мира вещей, поклонения этим вещам или фетишам. Несмотря на прогнозы Маркса относительно появления нового типа сознания, свободного от прежних заблуждений, в результате социальных изменений, религиозноподобное сознание оказалось устойчивым и направленным на обожествление новых объектов социального мира, вера в которых, по словам Э. Фромма, оказывается важнее, чем вера в Бога, т.е. буквально вопрос о вере в Бога становится второстепенным «по сравнению с тем, отрицает он идолов или нет» [11, с. 324].

В первую очередь под идолами Фромма следует понимать квазирелигиозные верования, концепцию которых первым разработал П. Тиллих. Опро- 
вергая неточность понимания квазирелигиозных верований как псевдоверований, Тиллих рассматривал их как верования, имеющие «подлинное сходство, основанное на тождестве элементов» с настоящей религией, предметом которой является божество, область трансцендентного. Квазиверования обожествляют явления социальной реальности, будь то «народ, наука, некоторая форма или этап развития общества, высший идеал человечества, которые при этом отождествляются» [12, с. 398-399]. Таким образом, они аутентичны подлинным религиям и представляют собой явления духовной жизни, выполняют религиозные функции [13, с. 310-311].

В отличие от западной социологии, исследующей проблемы квазирелигиозных верований в аспекте свободного времени, образа жизни, профессиональной и общественной деятельности, нетрадиционных восточных практик, отечественная наука традиционно описывает квазирелигию в рамках идеологии, культа личности, эсхатологии, преобразовательной деятельности человека. Ряд исследователей, например Л.А. Андреева, определяет временные рамки квазирелигии советским периодом, расцвет ее совпал с окончанием гражданской войны, со смертью Ленина, а завершился этот период в 1960-е годы, когда разоблачение «культа личности Сталина разрушило сакральную формулу наместнической власти» [14, с. 28, 32].

Данный вывод подтверждается социологическими исследованиями 2016 года, в ходе которых было опрошено 380 студентов очной и очно-заочной форм обучения Березниковского филиала ПНИПУ.

При высоком уровне доверия к В.Путину и его деятельности (58,4 \%) только 10,3 \% респондентов считают возможным появление культа личности в наши дни, невозможным - 42,5 \%, никогда не задумывались над проблемой $11,5 \%$, затруднились с ответом 7,0\%.

С тезисом Горького «человек звучит гордо, человек звучит великолепно» оказались согласны 11,3\% опрошенных, скорее согласны 9,8 \%; не согласны 48,7 \%; скорее не согласны 15,1 \%; никогда не задумывались над этим вопросом 8,9\%; затруднились с ответом 5,6\%.

В возможность построения светлого будущего верят только 6,6 \%; считают эту идею несостоятельной 53,7 \%; никогда не задумывались над вопросом $6,3 \%$, затруднились с ответом $4,8 \%$.

Сегодня религиозноподобное сознание в большей степени проявляется в аспекте потребительской деятельности, определяющей ритм повседневной жизни и интересы личности [15, с. 108], и предмета, вещи, которые воспринимаются как фетиш, достойный поклонения, средство для достижения жизненного успеха [16, с. 12-13].

Престижные вещи не утрачивают своего значения и в период кризиса, когда, как признали 14,4 \% опрошенных респондентов, большая часть семейного бюджета уходит на продукты питания; 8,8 \% отметили высокую стоимость ус- 
луг ЖКХ, которая негативно сказывается на доходах, еще 13,1 \% связали финансовые трудности своей семьи с необходимостью выплаты кредитов.

Тем не менее $37,5 \%$ считают, что, несмотря на трудности, необходимо тратить деньги на дорогие престижные вещи, которые положительно влияют на имидж их семьи, самого студента, повышают его статус в группе и среди друзей, а позднее позволят заявить о себе в профессиональном коллективе.

Среди престижных вещей лидирует iPhone 7. Этой модели отдали предпочтение 39,1 \% респондентов; 11,3 \% являются владельцами iPhone 6s; $16,7 \%$ имеют iPhone 5s; 9,7 \% студентов заявили, что им не важна модель, так как главное в этом вопросе наличие связи.

Автомобили имеют 29,3 \% студентов. Еще 13,2 \% опрошенных заявили о желании стать владельцем престижного чоппера - мотоцикла, популярного в среде байкеров; 8,7 \% мечтают о полной экипировке байкера, еще 3,4 \% считает достаточным для создания подходящего имиджа куртку-косуху, шлем и перчатки.

Характерные черты религиозноподобного типа сознания раскрываются в аспекте религиозной ситуации постсекулярного мира, который отрицает предшествующий секулярный период, но, одновременно, является и его последователем. В секулярный период в отсутствие влияния религиозных институтов и религиозной социализации формируются новые модели религиозного поведения, которые усваиваются, прежде всего, молодыми поколениями, а затем, с течением времени становятся образцами «нового образа жизни» для последующих поколений, так как они в большей степени соответствовали их жизненному опыту. Речь идет о «новом способе участия», по определению Ш. Эйзенштадта $[17$, с. 35], унаследованном постсекулярным периодом уже как устоявшимся и традиционным, который, с точки зрения культурного христианства, характеризуется неструктурированными знаниями о вере, редкими посещениями церковных богослужений, приоритетом личных интересов в свободном выборе элементов из религиозной культуры и дистанцированием не только от деятельности сект и нетрадиционных религий, но и от официальной церкви $[18$, с. 85], что подтверждается общероссийскими социологическими исследованиями, в течение нескольких лет устойчиво фиксирующими низкий уровень религиозности и воцерковленности [19, с. 30-33]

Данные социологического опроса 2016 года еще раз подтвердили сложившуюся тенденцию. Как следовало ожидать, православными себя признали 53,6 \% опрошенных студентов в соотношении с 17,8 \% колеблющихся, $10,1 \%$ атеистов, $8,9 \%$ убежденных атеистов, 7,2 \% затруднившихся с ответом.

Из числа студентов, идентифицировавших себя как православных верующих, Евангелие читали только 5,6 \%; церковные службы посещают один раз в неделю $3,3 \%$, один раз в две недели - 6,1 \%, один раз в месяц - $15,3 \%$, по большим праздникам - 20,9\%; 14,7 \% никогда не бывают в церкви. На ключевой вопрос для всех верующих о бессмертии и вечной жизни ответы разделились сле- 
дующим образом: верят в бессмертие души и вечную жизнь только 4,8 \%; не верят в бессмертие души и вечную жизнь 33,3 \%, еще 16,2 \% подозревают, что после окончания жизни существование человека не заканчивается, но приобретает какой-то новый качественный характер (8,2\%), верят в реинкарнацию $(8,0 \%)$; никогда не задумались над проблемой $4,5 \%$.

Не лучше обстоит дело с причастием, в этом обряде принимают участие только $2,3 \%$; но к молитве обращается подавляющее число респондентов $44,3 \%$. Поводом для молитвы является болезнь близких родственников (19,9\%), беспокойство, страх, неуверенность $(13,8 \%)$, трудный экзамен $(10,7 \%)$, сложная жизненная ситуация $(14,3 \%)$.

Таким образом, религиозноподобное сознание представляет собой тип сознания, для которого характерно восприятие православия и идентификация человека с ним вследствие национальной традиции, при наличии слабой мотивации на выполнение канонических обрядов и соблюдения религиозных правил и норм.

\section{Список литературы}

1. Чеснокова В.Ф. Тесным путем. Процесс воцерковления населения России в конце XX века. - М.: Академический Проект, 2005. - 304 с.

2. Пруцкова Е.В. Операционализация понятия «религиозность» в эмпирических исследованиях // Государство, религия и церковь в России и за рубежом. - 2012. - № 2 (30). - С. 277-278.

3. Дюркгейм Э. Элементарные формы религиозной жизни // Мистика. Наука. Религия. Классики мирового религиоведения: антология. - М.: Канон + ,1998. - Кн. 2. -432 с.

4. Вебер М. Избранное. Образ общества. - М.: Юрист, 1994. - 704 с.

5. Флоровский Г.В. Пути русского богословия. - М.: Институт русской цивилизации, 2009. $-848 \mathrm{c}$.

6. Бердяев Н.А. Судьба России. Опыт по психологии войны и национальности. - М.: Философское общество СССР, 1990. - 240 с.

7. Бёкк Р. Космическое сознание. - М.: Одиссей, 1995. - 344 с.

8. Скобцова Е.Ю. Типы религиозной жизни. - М.: Свято-Филаретовская высшая православно-христианская школа, 2002. -68 с.

9. Мертон Р. Социальная теория и социальная структура. - М.: АСТ: АСТ МОСКВА: Хранитель, 2006. - 873 с.

10. Файнбург 3.И. Развитие социалистического общества и научнотехническая революция: автореф. дис. ... д-ра филос. наук. - Ростов н/Д, 1972. $-36 \mathrm{c}$.

11. Фромм Э. Психоанализ и этика. - М.: Республика, 1993. -416 с.

12. Тиллих П. Избранное. Теология культуры. - М.: Юрист, 1995. -479 с. 
13. Колкунова К.А. Современные концепции квазирелигий // Вестник христианской гуманитарной академии. - 2014. - № 1. - Т. 15. - С. 305-313.

14. Андреева Л.А. Православие и коммунистическая квазирелигия // Социосфера. - 2010. - № 4. - С. 24-33.

15. Штомпка П. Социология социальных изменений. - М.: Аспект Пресс, 1996. - 416 c.

16. Бодрийяр Ж. Общество потребления его мифы и структуры. - М.: Республика, 2006. - 269 с.

17. Эйзенштадт Ш. Новые религиозные констелляции в структурах современной глобализации и цивилизационная трансформация // Государство, религия, церковь в России и за рубежом. - 2012. - № 1 (90). - С. 33-56.

18. Бреская О.Ю. Изучение религиозности: к необходимости интегрального подхода // Социологические исследования. - 2011. - № 12. - С. 77-87.

19. Синелина Ю.Ю. Религия и современное общество // Православие и современность: проблемы секуляризма и постсекуляризма. - М.: Орел. Ливны. Изд-во Новоспасского монастыря, 2015. - 456 с.

\section{References}

1. Chesnokova V.F. Tesnym putem. Protsess votserkovleniia naseleniia Rossii v kontse XX veka [In a close way. The churching of Russian population at the end of the 20th century]. Moscow, Akademicheskii Proekt Publ., 2005, 304 p.

2. Prutskova E.V. Operatsionalizatsiia poniatiia "religioznost" $\mathrm{v}$ empiricheskikh issledovaniiakh [The operationalization of the religiousness concept in empirical research]. Gosudarstvo, religiia i tserkov' v Rossii i za rubezhom, 2012, no. 2, vol. 30, pp. 277-278.

3. Diurkgeim E. Elementarnye formy religioznoi zhizni [Elementary forms of religious life]. Mistika. Nauka. Religiia. Klassiki mirovogo religiovedeniia. Antologiia. Moscow, Kanon+ Publ., 1998, vol. 2, 432 p.

4. Veber M. Izbrannoe. Obraz obshchestva [Selection. Image of the society]. Moscow, Iurist Publ., 1994, 704 p.

5. Florovskii G.V. Puti russkogo bogosloviia [Ways of Russian theology]. Moscow, Institut russkoi tsivilizatsii Publ., 2009, 848 p.

6. Berdiaev N.A. Sud'ba Rossii. Opyt po psikhologii voiny i natsional'nosti [The fate of Russia. Experience in the psychology of war and nationality]. Moscow, Filosofskoe obshchestvo SSSR, 1990, 240 p.

7. Bekk R. Kosmicheskoe soznanie [Cosmic consciousness]. Moscow, Odissei Publ., 1995, 344 p.

8. Skobtsova E.Iu. Tipy religioznoi zhizni [Types of religious life]. Moscow, Sviato-Filaretovskaia vysshaia pravoslavno-khristianskaia shkola Publ., 2002, 68 p.

9. Merton R. Sotsial'naia teoriia i sotsial'naia struktura [Social theory and social structure]. Moscow, AST MOSKVA: KhRANITEL' Publ., 2006, 873 p. 
10. Fainburg Z.I. Razvitie sotsialisticheskogo obshchestva i nauchno-tekhnicheskaia revoliutsiia [The development of socialist society and the scientific and technological revolution]. Abstract of Doctor's degree dissertation. Rostov-on-Don, 1972, 36 p.

11. Fromm E. Psikhoanaliz i etika [Psychoanalysis and ethics]. Moscow, Respublika Publ., 1993, 416 p.

12. Tillikh P. Izbrannoe. Teologiia kul'tury [Selection. Theology of Culture]. Moscow, Iurist, 1995, $479 \mathrm{p}$.

13. Kolkunova K.A. Sovremennye kontseptsii kvazireligii [Modern concepts of quasi-religions]. Vestnik khristianskoi gumanitarnoi akademii, 2014, no. 1, vol. 15, pp. 305-313.

14. Andreeva L.A. Pravoslavie i kommunisticheskaia kvazireligiia [Orthodoxy and communist quasi-religion]. Sotsiosfera, 2010, no. 4, pp. 24-33.

15. Shtompka P. Sotsiologiia sotsial'nykh izmenenii [Sociology of social changes]. Moscow, Aspekt Press Publ., 1996, 416 p.

16. Bodriiiar Zh. Obshchestvo potrebleniia ego mify i struktury [The myths and structures of consumer society]. Moscow, Respublika Publ., 2006, 269 p.

17. Eizenshtadt Sh. Novye religioznye konstelliatsii v strukturakh sovremennoi globalizatsii i tsivilizatsionnaia transformatsiia [New religious constellations in the structures of modern globalization and civilizational transformation]. Gosudarstvo, religiia, tserkov'v Rossii i za rubezhom, 2012, no. 1, vol. 90, pp. 33-56.

18. Breskaia O.Iu. Izuchenie religioznosti: k neobkhodimosti integral'nogo podkhoda [Study of religiousness: the need for the integrated approach]. Sotsiologicheskie issledovaniia, 2011, no. 12, pp. 77-87.

19. Sinelina Iu.Iu. Religiia i sovremennoe obshchestvo [Religion and modern society]. Pravoslavie i sovremennost': problemy sekuliarizma i postsekuliarizma. Moscow, Orel. Livny. Novospasskii monastyr', 2015, 456 p.

Оригинальность статьи - $93 \%$

Получено 22.12.2016

\author{
I.M. Pudovkina
}

\title{
THEORETICAL UNDERPINNING OF TYPES OF A POLYSEMANTIC CONCEPT OF RELIGIOUS CONSCIOUSNESS
}

The article considers theoretical approaches to the classification of religious consciousness and its typology. Special emphasis is laid on the concept of religious-like consciousness that reflects the understanding of religion in collective consciousness, influenced by secular factors. Nowadays the study of post-secular reality appears relevant, as it raises the issues of the relations between religion and modern religious consciousness, with their paradoxical and at times opposing arguments. Recent social studies have been preoccupied with secularization theories that postulated the incompatibility of reli- 
gious and secular world views. The latter were given the indisputable right for existence, while the former were shifted to the private sphere of life. The authors claim that post-secular society brings religion back to its place and considers it a possible alternative in the perception of the world. According to $S$. Eisenstadt, compared to secular society post-secular society is characterized to a greater degree with a "multitude of contemporaneities". The very existence of them is critical for the formation of the religious consciousness type, which is the most accurate reflection of contemporary religious situation. In other words, religious-like consciousness is developed under the influence of both religious and secular traditions, as well as quasi-religions, non-traditional religious movements and personal preferences defining self-identification of an individual. The results of the sociological research emphasize the main features of religious-like consciousness as a characteristic consciousness type of modern time.

Keywords: religious consciousness, types of religious consciousness, religious-like consciousness, quasi-religion, religiousness.

Irina M. Pudovkina - Senior Lecturer, Dept. of General Scientific Disciplines, Perm State National Research University (Berezniki branch), e-mail: iri14250591@yandex.ru. 